\title{
Inhaler choice in primary practice
}

\author{
K.R. Chapman*, T.H. Voshaar\# and J.C. Virchow"
}

ABSTRACT: A broad range of inhaler devices is available for physicians to prescribe. Although newer devices are often easier to use than conventional pressurised metered-dose inhalers (pMDls), many patients still use inhalers sub-optimally. Physicians must become familiar with the characteristics of several inhalers and choose the device that their patients can use correctly and beneficially if they are to prescribe successfully to those with chronic obstructive pulmonary disease (COPD). The selection of a device may also be influenced by patient comorbidities and by their ability to handle and inhale correctly from the device. A further challenge in the COPD setting is measuring the desired treatment outcome.

A simple algorithm or checklist can guide device selection in primary care. The device must be affordable for the patient, the patient must be able to handle it correctly and the practitioner or other trained professional should monitor that it is being used correctly. The patient's and physician's preferences should also be taken into account. The most important device-handling skills that should be assessed are whether the patient can: properly prepare and actuate the device; take an adequate inspiration; and coordinate actuation of a pMDI with inspiration.

Testing the practicality and advantages of such checklists will mean better use can be made of the inhaler types currently available as well as newer designs. In the interim, caregiver and patient education are needed.

KEYWORDS: Asthma, chronic obstructive pulmonary disease, deposition, dry powder inhaler, inhaler technique, pressurised metered-dose inhaler

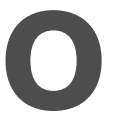
ver the next decade, chronic obstructive pulmonary disease (COPD) is expected to become the third most common cause of death in the world [1]. The rising prevalence of both COPD and asthma means treatment of obstructive airway diseases will continue to be a common management challenge for primary practitioners in ambulatory care settings, as well as clinicians in hospital settings. Guidelines for obstructive airway diseases rely increasingly on management with inhaled rather than oral or parenteral medications $[2,3]$. The once ubiquitous quick-relief bronchodilator delivered by pressurised metered-dose inhaler (pMDI) has given way to a bewildering array of drugs, delivery devices, add-on devices (spacers) and drug/device combinations. Given the increasing importance and complexity of inhaler selection, this review has been undertaken with the goal of developing a simple algorithm or tool to guide inhaler choice for patients with COPD.

The majority of patients with COPD or asthma receive their respiratory care in a primary care practice setting: in North America, $\sim 80-85 \%$ of such patients receive care from a primary care practitioner alone and do not see a specialist $[4$, 5]. Visits to a primary practice are typically brief. For a patient with a respiratory disease, the 5- or 10-minute encounter could encompass diagnosis, assessment of control, review of medication usage, physical examination, measurement of lung function, prescription and education. For the older patient with COPD, common comorbidities might also be assessed. Due to time pressures, the selection of an inhaler device and training the patient in its correct use may be delegated explicitly or implicitly. A substantial proportion of patients may receive no inhaler instruction. In one primary practice audit of asthma management undertaken in Canada, $28 \%$ of 6,684 patients reported never having demonstrated their inhaler technique to a healthcare professional [6]. Moreover, physicians seem complacent about this neglect: 221 Canadian physicians who participated in the same practice audit estimated that $25 \%$ of their patients had never demonstrated their inhaler technique [6]. This Review focuses on the needs of the patient with COPD, but no inhaler choice algorithm intended for primary practice can remain practical if it ignores other diseases and age groups, and many principles of inhaler use in COPD patients are, fortunately, common to patients with asthma, as are the errors in inhaler technique [7]. Unfortunately, there is a dearth of inhaler research specific to patients with COPD
AFFILIATIONS

*University Health Network, Toronto, ON, Canada, and

\#Dept of Pneumology and Allergy, Medical Clinic III, Bethanien Hospital, Moers, and

'Dept of Pneumology, University Medical Clinic, Rostock, Germany.

CORRESPONDENCE

K.R. Chapman

Asthma and Airway Centre University Health Network Room 7E-451 399 Bathurst Street Toronto ON

Canada M5T 2S8 Fax: 14166033456 E-mail: kchapman@ca.inter.net 
and therefore it is necessary to extrapolate cautiously from research undertaken in patients with asthma, both stable and acutely ill.

\section{PATIENT AND CAREGIVER KNOWLEDGE OF INHALERS}

Numerous studies have identified sub-optimal inhaler technique as a common problem in patients with respiratory disease $[8,9]$. Early studies clearly showed that patients struggled with conventional pMDIs. Although many errors in handling were detected by investigators, the most common was difficulty coordinating device actuation and inhalation [10]. Investigators working in referral centres, such as pulmonary function laboratories, have estimated that between $14-89 \%$ of patients seen for the first time will use their inhalers sub-optimally [9, 11]. On average, about one-third of patients assessed in a specialised centre do not use their inhaler to good advantage. However, if these studies are examined critically, it becomes clear that not all handling errors are crucial. For example, although failure to remove the cap from a pMDI before use will clearly render it useless, failing to shake the device before the second of two sequential inhalations may have little effect on drug delivery. Dry powder inhalers (DPIs) have been studied more recently $[12,13]$ and although they are thought to be easier to use than pMDIs, there are still potential problems when patients attempt to use them. Most importantly, some patients fail to generate inspiratory flow rates that are high enough to deliver sufficient drug to the lungs. This is certainly the case with most children $<6$ yrs of age. Many examples of DPI mishandling by adult and adolescent patients have also been reported [14,15]. Some will hold the device in the wrong position when loading the dose or inhaling, and others may shake the device after priming it or tap some of the powder on to their hand to check that a dose has been dispensed, thereby dispersing the powder before it can be inhaled. Other patients may attempt to use an open-mouth inhalation technique with a DPI. As with pMDIs, some ways of mishandling a DPI may reduce efficacy slightly while others may render the device useless. In the literature, there is little consensus for any device as to what constitutes a crucial handling error.

How crucial different handling errors are may also depend upon the drug being delivered. In general, bronchodilators may be more resistant to improper inhaler use than inhaled corticosteroids (ICS), although this is difficult to assess clinically. This may be because recommended bronchodilator dosages are on the plateau of the dose-response curve so that even sub-optimal delivery results in a clinically meaningful, if not maximal, effect. Patients who do not notice an effect after one dose of bronchodilator often continue dosing until they do. In the case of $\beta_{2}$-agonists, an error resulting in poor deposition may be less crucial because the rich endobronchial microcirculation may redistribute absorbed drug.

Although there are many papers that describe patients' handling of inhalation devices, fewer focus on their preference for different devices. Most studies of preference are performed somewhat crudely and typically use unvalidated scoring systems for assessing preference. In some studies, patients seem to prefer a new inhaler over an existing device for reasons that bear little relevance to its efficacy, such as novelty, colour or shape. In addition, companies with a commercial interest in the device under test have sponsored a large majority of these papers. The subject of measuring preference is dealt with in an accompanying paper in this Review [16].

Given our increasing reliance on inhaled medications as the foundation of care for asthma and COPD, and the wellknown phenomenon of patient inhaler mishandling, a wellestablished educational approach for prescribing inhalers to patients could be expected. Regrettably, studies suggest that many caregivers are unfamiliar with correct inhaler technique $[17,18]$. Although physicians are the least adept of caregivers at handling inhalers, even respiratory ward nurses and respiratory therapists may make mistakes in device technique, particularly with newer devices. Pharmacists charged with dispensing inhalers may also have difficulty instructing patients correctly $[19,20]$.

\section{SPECIAL CONSIDERATIONS IN COPD}

Patients with COPD may present special problems when the prescribing physician comes to select an inhalation device. Most obviously, the majority of patients with COPD are advanced at the time of diagnosis. Their severe expiratory airflow limitation is typically accompanied by decreased inspiratory capacity, hyperinflation and respiratory muscles that work at a mechanical disadvantage. All of these factors combine to reduce inspiratory flow rates, which could diminish lower airway deposition of drug if inhaled from a DPI. Most DPIs are designed to ensure that drug delivery is adequate even at relatively low inspiratory flow rates and that the device offers little resistance to the struggling patient [21]. However, devices vary in their flow characteristics, with some requiring higher pressure drops to disperse the powder into particles of respirable size [22]. Most COPD patients are middle-aged or older and some of the more severely affected patients are elderly. Although advanced age alone is not thought to be a major factor in how patients handle an inhaler device [23], the comorbidities suffered by COPD patients in advanced age should be considered when choosing an inhaler, as they may markedly affect handling. For example, patients with arthritis will struggle with pMDIs because actuation (pressing on the canister) may be difficult. Similarly, patients with neuromuscular disease may have handling or inhalation problems [23].

The greatest challenge for inhaler selection in COPD is determining efficacy. By definition, patients with COPD are less responsive to bronchodilators than patients with asthma. The effect of an inhaled bronchodilator in an asthma patient can be demonstrated in only a few minutes using spirometry. In the patient with COPD, spirometric changes are much smaller and vary from day to day. GUYATT et al. [24] have shown clearly that the response to inhaled $\beta_{2}$-agonists on any given day is a poor guide to responsiveness on any other day. Even longer-term responses to potent systemic agents such as oral corticosteroids are challenging to interpret and may bear little relationship to the patients' responses to ICS over time. In the absence of rapidly and easily measured spirometric outcomes, most clinicians rely upon subjective patient responses to guide bronchodilator prescription. ICS prescriptions for the COPD patient tends to be guided by general principles and the clinician's assessment of exacerbation rate. More recently, end-points used in clinical trials have included increased inspiratory capacity, reduced dynamic hyperinflation, improved exercise tolerance or decreased 
exacerbation rate. Such outcomes, however, are not currently validated as practical assessments for use by a prescribing primary care physician.

The decreased inspiratory and expiratory flow rates and decreased inspiratory capacity of the COPD patient may also pose problems for the practitioner attempting to evaluate correct inhaler technique. A recent study has compared patient handling of a conventional and a breath-actuated pMDI in elderly patients, half of whom had never used an inhaler [25]. Inhaler handling was monitored in a conventional subjective fashion (by trained technologists), and by a simple inhalationmonitoring device that recorded when device actuation occurred and measured inspiratory volume. The authors discovered that trained technologists sometimes failed to notice inadequate technique; patients who appeared to inhale adequately were inhaling too rapidly, too slowly or with inadequate volume. Even when such errors are imperceptible to the trained observer, an objective monitoring device can detect them readily. Although such devices have become available for use in office settings, this remains uncommon, with the risk that inadequate inhaler technique may go undetected.

\section{THE FUNDAMENTALS OF INHALER CHOICE}

Several general principles of inhaler selection and use can be derived from the medical literature and have recently been reviewed in detail by a joint committee of the American College of Chest Physicians (ACCP) and the American College of Asthma, Allergy and Immunology (ACAAI) [26].

In brief summary, pMDIs are convenient for delivering a wide variety of drugs to a broad spectrum of patients. The crucial steps in technique appear to be inhalation from functional residual capacity or residual volume, timed to coincide with device actuation and at a reasonably slow and steady inspiratory flow rate. A breath-hold of 5-10 seconds may increase drug deposition but may not be crucial for efficacy. For patients who have trouble coordinating inhalation with device actuation, the use of a spacer (with a valve) may obviate this difficulty, though most of these devices are cumbersome to store and transport. The use of spacers, however, is mandatory for infants and young children. DPIs are usually easier for patients to handle and a growing number of drug types are available in several DPI formats. The key issue for dry powder inhalation is adequate inspiratory flow rate. The most severely ill patients and the very young may not be candidates for a DPI. Gas-driven nebulisers can be used by almost any patient, in a variety of clinical settings from the home to the intensive care unit for the intubated and ventilated patient. However, nebulisers are more expensive, cumbersome and relatively time-consuming to use, compared with handheld devices. Most gas-driven nebulisers require time for dose preparation and loading, and $\sim 20$ minutes for inhalation. These attributes can and should limit the use of nebulisers whose effect can be matched by handheld devices in almost all clinical settings.

A new type of device that further expands the range from which physicians can choose is the soft mist inhaler. Such inhalers use a variety of means other than compressed gas, to produce a very fine liquid aerosol (a "soft mist") from a handheld device. In the case of the Respimat ${ }^{\circledR}$ Soft Mist ${ }^{\mathrm{TM}}$
Inhaler (Boehringer Ingelheim \& Co. KG, Ingelheim, Germany), for example, a metered dose of drug solution is forced by the energy of a compressed spring through a nozzle system (the "uniblock"), producing two fine jets of liquid that converge at a preset angle and collide to generate the soft mist [27]. Respimat ${ }_{\circledast}$ Soft Mist ${ }^{\mathrm{TM}}$ Inhaler appears to be easy to use: dosing requires a single inhalation and produces greater lower airway deposition than conventional pMDIs [28]. Although a wide range of compounds have yet to be tested in soft mist inhalers, available studies on Respimat ${ }^{\circledR}$ Soft Mist ${ }^{\mathrm{TM}}$ Inhaler suggest that the high lung deposition enables the desired clinical effect to be achieved with lower nominal doses and without propellant or adjuvants that might provoke adverse effects [29-34].

\section{POSSIBLE APPROACHES TO INHALER SELECTION}

Relatively little research has been carried out on how primary practitioners select inhalers. Anecdotal evidence suggests that many practitioners choose to become familiar with a single type of inhaler and prescribe it exclusively. Certainly, for many years in Western nations, the pMDI was the most commonly prescribed handheld inhaler. The obvious drawbacks to the "one size fits all" approach are that either patients will use the selected device sub-optimally or that the compound best suited to the patient's therapeutic needs will not be available in the selected device. Some physicians prescribe more than one type of inhaler, but delegate the task of monitoring inhaler technique to others. If the responsibility is delegated explicitly to an asthma educator, the treatment outcomes are likely to be reasonable [18]. Often, though, the delegation is implicit and the intended education and monitoring may not happen. As noted above, pharmacists charged with the task of dispensing inhalers may be unfamiliar with their use and may be illequipped to teach their optimal use to patients [19]. A better strategy would be for physicians to become familiar with more than a single inhaler and, ideally, with all the available inhalers that their patients may need. The ability to prescribe more than one type of inhaler will allow primary practitioners to select the one best suited to their patient's needs; implicitly, the physician will require a method for selecting this device.

\section{Is a checklist the best approach for device selection?}

As well as providing evidence-based recommendations on device selection, the recent guidelines produced by the ACCP / ACAAI committee reviewed device selection [26] and suggested that when physicians select an aerosol delivery device they must consider eight questions (table 1). Several questions may be helpful in the selection process, but an eight-question checklist seems unduly cumbersome for day-to-day use. Moreover, the list seems to contain some redundant items and yet be incomplete in other areas. The present authors offer the following comments.

Questions 1 and 3 are similar. Physicians must be aware of which available devices deliver their chosen compound to the patient and whether such devices are affordable for the patient to purchase either directly or through an appropriate reimbursement mechanism. These overlapping questions of regulatory availability, formulary listing and cost can be distilled into a single question concerning availability, i.e. "In what device is the chosen drug available and affordable for my 


\section{TABLE 1 Checklist for physician selection of inhalers proposed by a joint committee of the American College of Chest Physicians and American College of Asthma, Allergy and Immunology (adapted from [26] with permission from the publisher)}

1 In what devices is the desired drug available?

2 What device is the patient likely to be able to use properly, given the patient's age and the clinical setting?

3 For which device and drug combination is reimbursement available?

4 Which devices are the least costly?

5 Can all types of inhaled asthma/COPD drugs that are prescribed for the patient be delivered with the same type of device?

6 Which devices are the most convenient for the patient, family or medical staff to use given the time required for drug administration and device cleaning, and the portability of the device?

7 How durable is the device?

8 Does the patient or clinician have any specific device preferences?

patient?" A cost issue also appears to be addressed in question 4 of the original checklist, "Which devices are the least costly?" This is a challenging question for the primary practitioner: does this mean acquisition cost alone or does it imply that the device should be cost-effective? In the absence of reliable studies on the cost-effectiveness of various drug/device/ disease combinations specific to all jurisdictions, it is felt that this question should be omitted.

Question 2 in the original checklist asks whether the patient is "likely" to be able to use the device properly given the patient's age and the clinical setting. This question assumes that the physician is skilled enough to estimate the likelihood of success with the given inhaler, and implies that the patient will receive training on how to use it, either from the physician or another member of the healthcare team. Indeed, the assessment of technique itself may need to be delegated to another if it is to be fully effective. Thus, a further question should be added to the checklist (see question 2 in table 2), to identify who will be responsible for the assessment, training and monitoring of technique over time. Whoever this person is, some additional guidance should be provided to them in selecting a suitable device, a subject that is addressed in the next section.

A recommendation implied by question 5 of the original checklist is that physicians should attempt to prescribe a single type of inhalation device when more than one drug is prescribed. The use of different inhaler devices means that more resources are needed to train the patient. In addition, it has been shown that patients using two devices requiring different techniques may confuse the correct techniques for

\section{TABLE 2 Proposed checklist to guide inhaler selection in primary care}

1 In what device is the chosen drug available and affordable for my patient?

2 Who will teach the patient the correct inhaler technique?

3 Does the patient or physician have a preference for one type of device, assuming that the device/drug combination is available, affordable and can be handled correctly by the patient after education? each [35], but there is little evidence to suggest that this is a critical problem in practice. It is equally plausible that patients who use more than one drug/device combination for different purposes might find it easier to distinguish between them if they are different types of device. Given the scarcity of evidence in this area, it seems reasonable to suggest prescribing a single type of device for patients who use more than one inhaler is a matter of physician/patient preference.

Question 6 of the original questionnaire concerns the convenience of use by caregivers charged with helping patients to inhale their medications, which is an important consideration in a long-term treatment setting. Question 7, concerning the durability of the device, may be applicable to or of concern for devices that are reused over long periods of time such as gasdriven nebulisers, but not for handheld inhalers that are expected to have a limited period of use. Finally, as described in the preceding paper in this Review [16], the issues of patient and physician preference (question 8) are poorly studied. However, as the last and least of the criteria for choosing a device, it would seem helpful for patients and their physicians to have some enthusiasm for the selected device if adherence with the prescription is to be optimal. The patient's willingness to take regular inhaled treatment should be assessed, and a joint selection of devices that are easy to use, together with further education, may overcome any initial reluctance.

A subject not addressed in the checklist produced by the ACCP/ACAAI committee is the environmental aspect of device use. Chlorofluorocarbons (CFCs) released from pMDIs and the waste generated by discarded devices is of concern in some parts of the world, and some physicians and patients may prefer devices that can be reused or refilled.

Table 2 shows a revised checklist that is greatly simplified for the primary practice setting. The revised checklist addresses the practical availability and affordability of a drug-device combination, the patient's ability to use it and the patient's and physician's preference for it.

\section{An algorithmic approach to device selection}

As mentioned above, the process of device selection by a primary care physician or another professional with the requisite skills will involve assessment of the patient's abilities in a simple fashion and the modification of inhaler choice accordingly, i.e. the use of a device algorithm. Two examples of algorithms suggested by VOSHAAR et al. [36] and VIRCHOW et al. [37] start from a different reference point to the primary care consultation, and are applicable to patients in any setting, including the hospital. However, both include elements that could be incorporated into a primary care algorithm, namely that some assessment needs to be made of how well patients can inspire, how well they can coordinate device actuation with inspiration and recommendations on the environmental impact of devices. The current authors suggest a new algorithm that combines these points with other patient assessment steps, as follows.

- Assess whether the patient can take an adequate inspiration that generates a flow rate $>30 \mathrm{~L} \cdot \mathrm{min}^{-1}$ for a significant portion of the inspiratory breath. Without access to a suitable inhalation monitoring device (described above), the physician will need to make the decision based upon 


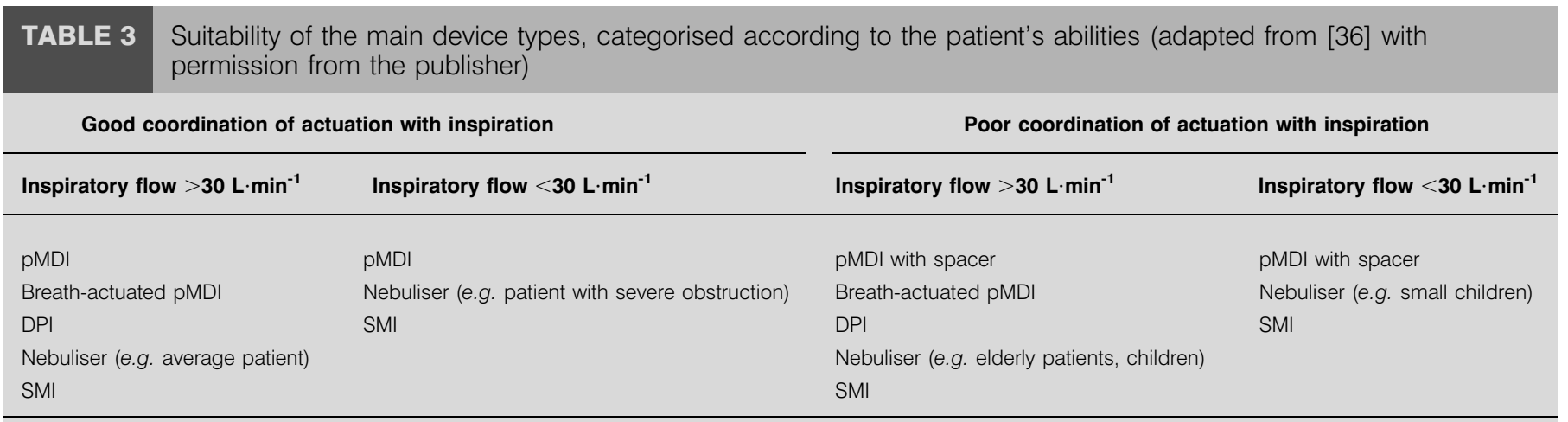

pMDI: pressurised metered-dose inhaler; DPI: dry powder inhaler; SMI: soft mist inhaler

inspection of the patient's inspiratory effort, perhaps with the help of a placebo device. Where inadequate flow is suspected, e.g. in patients with severe disease or with poor respiratory efforts caused by comorbidity, DPIs and breath-actuated devices should be avoided.

- Assess the patient's ability to coordinate actuation of the pMDI with early inspiration. Up to $60 \%$ of subjects might initially have difficulty with this, but half of these will learn after one or more practice session with an instructor (usually a nurse or pharmacist). However, some will "relapse"; for these, together with those that initially fail, an alternative inhaler should be considered. In general, the longer it takes to instruct a patient, the more likely it is that they will relapse or fail, and where there is doubt, it is preferable to choose an alternative device.

- Assess the patient's ability to prepare and actuate the device (including physical limitations caused by arthritis, weakness etc.) or their ability to learn such steps (cognitive impairment or other disability).

- Assess ease of learning additional, non-crucial steps in pMDI use, namely: shaking the canister; unhurried steady inspiratory effort; breath-holding for $10 \mathrm{~s}$ after full inspiration; use of a single puff per breath.

- To minimise the impact on the environment (i.e. ozone depletion), only CFC-free devices should be used.

Table 3, adapted from the algorithm published by VOSHAAR et al. [36], categorises the suitability of device types discussed earlier in this article according to inspiratory flow and coordination skill. Although the use of a spacer and valve with a pMDI can help patients who are poor at coordination, a large proportion of patients who are advised to use spacers fail to do so, because the devices are cumbersome and because patients are uncertain about practical issues such as cleaning or whether the spacer needs to be carried with them (which is impractical for most). For patients with COPD, the regular dosing required with bronchodilators makes them particularly unsuitable.

\section{QUESTIONS THAT NEED TO BE ANSWERED}

Although much of the respiratory community is aware that patient use of inhalers is often sub-optimal, there are many unanswered questions about the selection of inhalation devices. There is clearly a need to determine the impact of inhaler choice on compliance and clinical outcome. Literature in the asthma field suggests that sub-optimal inhaler technique is associated with poor outcome [38], but less is known about the impact of inhaler choice and inhaler handling on outcome in patients with chronic obstructive pulmonary disease. Similarly, little is known about the effect of patient preference for a given inhaler type on treatment outcomes. As already stated, it will be challenging to select outcomes that are feasible for use in the primary practice setting to determine whether inhaler choice for a chronic obstructive pulmonary disease patient has been successful. Once this is done, however, it will be possible to test the value of a checklist, such as that proposed above, to guide primary practitioners in device selection for patients with chronic obstructive pulmonary disease and possibly for patients with other respiratory diseases.

\section{SUMMARY}

- Primary practitioners should familiarise themselves with the characteristics of several inhalers and choose a device that a chronic obstructive pulmonary disease patient can use correctly and that will be of benefit to them.

- The selection of a device for a chronic obstructive pulmonary disease patient may be influenced by patient comorbidities as well as by the patient's ability to handle the device and perform the necessary inhalation manoeuvres.

- When selecting a device for the patient with respiratory disease, the primary practitioner should check that it is affordable and that the patient can handle it correctly. The patient's and physician's preferences should also be taken into account.

- The patient's ability to handle a device should be assessed by the practitioner or other trained professional. They should also assess whether the patient can properly prepare and actuate the device, take an adequate inspiration and coordinate actuation of a pressurised metered-dose inhaler with inspiration.

\section{REFERENCES}

1 Murray CJ, Lopez AD. Alternative projections of mortality and disability by cause 1990-2020: Global burden of disease study. Lancet 1997; 349: 1498-1504.

2 Pauwels RA, Buist AS, Calverley PMA, Jenkins CR, Hurd SS. Global strategy for the diagnosis, management, and prevention of chronic obstructive pulmonary disease. NHLBI/WHO Global Initiative for Chronic Obstructive 
Lung Disease (GOLD) Workshop Summary. Am J Respir Crit Care Med 2001; 163: 1256-1276.

3 Sheffer AL, Bousquet J, Busse WW, et al. International consensus report on diagnosis and mangement of asthma. Publication \#92-3091. Bethesda, U.S. Department of Health and Human Services, 1992.

4 Chapman KR, Bourbeau J, Rance L. The burden of COPD in Canada: results from the Confronting COPD survey. Respir Med 2003; 97: Suppl. C, S23-S31.

5 ChapmanKR, ErnstP, GrenvilleA, DewlandP,ZimmermanS. Control of asthma in Canada: failure to achieve guideline targets. Can Respir J 2001; 8: Suppl. A, 35A-40A.

6 Chapman KR, Boulet LP, Rea R. Physician self-audit of asthma control in primary practice: the implications for implementation of guidelines. Am J Respir Crit Care Med 2004; 169: A362.

7 Hesselink AE, Penninx BW, Wijnhoven HA, Kriegsman DM, van Eijk JT. Determinants of an incorrect inhalation technique in patients with asthma or COPD. Scand J Prim Health Care 2001; 19: 255-260.

8 Coady TJ, Davies HJ, Barnes P. Evaluation of a breath actuated pressurized aerosol. Clin Allergy 1976; 6: 1-6.

9 Epstein SW, Manning CP, Ashley MJ, Corey PN. Survey of the clinical use of pressurized aerosol inhalers. Can Med Assoc J 1979; 120: 813-816.

10 Coady TJ, Stewart CJ, Davies HJ. Synchronization of bronchodilator release. Practitioner 1976; 217: 273-275.

11 Paterson IC, Crompton GK. Use of pressurised aerosols by asthmatic patients. BMJ 1976; 1: 76-77.

12 De Boeck K, Alifier M, Warnier G. Is the correct use of a dry powder inhaler (Turbohaler) age dependent? J Allergy Clin Immunol 1999; 103: 763-767.

13 Hansen OR, Pedersen S. Optimal inhalation technique with terbutaline Turbuhaler. Eur Respir J 1989; 2: 637-639.

14 Kamps AW, van Ewijk B, Roorda RJ, Brand PL. Poor inhalation technique, even after inhalation instructions, in children with asthma. Pediatr Pulmonol 2000; 29: 39-42.

15 Epstein SW, Maidenberg A, Hallett D, Khan K, Chapman KR. Patient handling of a dry-powder inhaler in clinical practice. Chest 2001; 120: 1480-1484.

16 Anderson P. Patient preference for and satisfaction with inhaler devices. Eur Respir Rev 2005; 14: 109-116.

17 Kelling JS, Strohl KP, Smith RL, Altose MD. Physician knowledge in the use of canister nebulizers. Chest 1983; 83: 612-614.

18 Hanania NA, Wittman R, Kesten S, Chapman KR. Medical personnel's knowledge of and ability to use inhaling devices. Metered-dose inhalers, spacing chambers, and breathactuated dry powder inhalers. Chest 1994; 105: 111-116.

19 Kesten S, Zive K, Chapman KR. Pharmacist knowledge and ability to use inhaled medication delivery systems. Chest 1993; 104: 1737-1742.

20 Jackevicius CA, Chapman KR. Inhaler education for hospital-based pharmacists: how much is required? Can Respir J 1999; 6: 237-244.

21 Nsour WM, Alldred A, Corrado J, Chrystyn H. Measurement of peak inhalation rates with an in-check meter to identify an elderly patient's ability to use a turbuhaler. Respir Med 2001; 95: 965-968.
22 Newman SP. Inhaler treatment options in COPD. Eur Respir Rev 2005; 14: 102-108.

23 Goodman DE, Israel E, Rosenberg M, Johnston R, Weiss ST, Drazen JM. The influence of age, diagnosis, and gender on proper use of metered-dose inhalers. Am J Respir Crit Care Med 1994; 150: 1256-1261.

24 Guyatt GH, Townsend M, Nogradi S, Pugsley SO, Keller JL, Newhouse MT. Acute response to bronchodilator. An imperfect guide for bronchodilator therapy in chronic airflow limitation. Arch Intern Med 1988; 148: 1949-1952.

25 Chapman KR, Love L, Brubaker H. A comparison of breathactuated and conventional metered-dose inhaler inhalation techniques in elderly subjects. Chest 1993; 104: 1332-1337.

26 Dolovich MB, Ahrens RC, Hess DR, et al. Device selection and outcomes of aerosol therapy: Evidence-based guidelines: American College of Chest Physicians / American College of Asthma, Allergy, and Immunology. Chest 2005; 127: 335-371.

27 Dalby R, Spallek M, Voshaar T. A review of the development of Respimat Soft Mist Inhaler. Int J Pharm 2004; 283: 1-9.

28 Newman SP. Use of gamma scintigraphy to evaluate the performance of new inhalers. J Aerosol Med 1999; 12: Suppl. 1, S25-S31.

29 Hodder R, Pavia D, Dewberry $\mathrm{H}$, et al. Low incidence of paradoxical bronchoconstriction in asthma and COPD patients during chronic use of Respimat ${ }^{\circledR}$ Soft Mist ${ }^{\mathrm{TM}}$ inhaler. Respir Med 2005; 99: 1087-1095.

30 Voshaar T, Hausen T, Kardos P, et al. [Inhalation therapy with Respimat soft inhaler in patients with COPD and asthma]. Pneumologie 2005; 59: 25-32.

31 Koehler D, Pavia D, Dewberry H, Hodder R. Low incidence of paradoxical bronchoconstriction with bronchodilator drugs administered by $\operatorname{Respimat}_{\circledast}$ Soft Mist ${ }^{\mathrm{TM}}$ inhaler: results of phase II single-dose crossover studies. Respiration 2004; 71: 469-476.

32 Kilfeather SA, Ponitz HH, Beck E, et al. Improved delivery of ipratropium bromide/fenoterol from Respimat ${ }$ Soft Mist ${ }^{\mathrm{TM}}$ Inhaler in patients with COPD. Respir Med 2004; 98: 387-397.

33 Vincken W, Bantje T, Middle MV, Gerken F, Moonen D. Long-term efficacy and safety of ipratropium bromide plus fenoterol via Respimat ${ }$ Soft Mist ${ }^{\mathrm{TM}}$ Inhaler (SMI) versus a pressurised metered-dose inhaler in asthma. Clin Drug Invest 2004; 24: 17-28.

34 von Berg A, Jeena PM, Soemantri PA, et al. Efficacy and safety of ipratropium bromide plus fenoterol inhaled via Respimat ${ }^{\circledR}$ Soft Mist ${ }^{\mathrm{TM}}$ Inhaler vs. a conventional metereddose inhaler plus spacer in children with asthma. Pediatr Pulmonol 2004; 37: 264-272.

35 van der Palen J, Klein JJ, van Herwaarden CL, Zielhuis GA, Seydel ER. Multiple inhalers confuse asthma patients. Eur Respir J 1999; 14: 1034-1037.

36 Voshaar T, App EM, Berdel D, et al. [Recommendations for the choice of inhalatory systems for drug prescription]. Pneumologie 2001; 55: 579-586.

37 Virchow JC Jr, Kroegel C, Matthys H. What is on the horizon? Clin Pharmacokinet 1994; 27: 85-93.

38 Giraud V, Roche N. Misuse of corticosteroid metered-dose inhaler is associated with decreased asthma stability. Eur Respir J 2002; 19: 246-251. 